Workshop 4

\title{
Teaching Design-Oriented Analysis at the First Level
}

\author{
R. David Middlebrook \\ California Institute of Technology
}

A common experience among new graduate electrical engineers is that, when faced with a real design problem, they "fall off a cliff" because they find that Design is the Reverse of Analysis, and that real problems are at least an order of magnitude more complicated than those they are familiar with.

A second-level active circuits course has been highly successful in implementing a Design-Oriented Analysis approach in which detailed and specific techniques have been made available to working engineers.

This Workshop will address two questions:

1. Can or should these Methods of Design-Oriented Analysis be incorporated in a first-level active circuits course;

2. If so, how can this best be done, and with what balance with conventional methods?

Despite the fact that graduates of electrical engineering programs have been exposed to a large amount of technical theory and practice, they still find themselves poorly equipped to handle the design problems they are faced with in industry. Even though for four or more years they have felt as though they have been "drinking from a firehose," they often don't know where to start when presented with their first job assignment. Typically, a new graduate engineer tackles a design problem as an exercise in analysis, which soon goes into algebraic paralysis.

Employers in the electronics field and ABET evaluators call for more design training at the university level, yet when it comes to practical specifics, the design process is too often ill-defined or not well understood.

In many years of teaching a second-level design course at Caltech I have developed a Design-Oriented Analysis approach in which the design objective is kept in view from the start, and maintained throughout the process.

出 In recent years, this approach has been adapted to short $m$ courses presented to working engineers in industry. In either context, it is an "after-the-fact" course, in which it is realized - that many ingrained approaches need to be modified and even discarded. Typical attendee comments are "Why didn't I get this in school?" and "This is the most useful class I've ever taken."

I believe that the Design-Oriented Analysis approach can help instructors prepare graduates for the transition from student to engineer more effectively and efficiently. Towards this end I have begun to work towards the goal of getting the vocabulary and techniques of Design-Oriented Analysis into the academic mainstream, specifically in papers presented at FIE '91 [1] and FIE '92 [2].
My objectives for this Workshop are:

1. Can the Design-Oriented Analysis paradigm, successful at a second-level and working engineer level, be equally successful if adopted in a first-level active circuits course?

2. If so, a different perspective must be employed. How can this be done?

I propose a loose agenda in which I'll start out by presenting my "case" for the Design-Oriented Analysis approach, and going into some of the specific techniques and examples, by which I hope to convince participants that this is a useful approach in its present form for second-level and higher courses. The essence of the approach is replacement of the usual negative attitude "I don't have enough equations to solve for the number of unknowns" by the positive attitude "I need to make the few equations I have work harder, and I need to substitute the missing equations with inequalities, tradeoffs, and approximations." Making an equation work harder is accomplished by putting it (preferably, by deriving it) in Low-Entropy form [1] paradigm:

Some principles of the Design-Oriented Analysis

1. A design analysis must be managed or structured to guide the analysis efficiently towards the desired goal.

2. The desired final form of the answer shapes the initial setup of the problem.

3. A properly organized equation can yield valuable, often critical, information on circuit behavior without any numerical calculation.

4. Put only enough into the model to get the answer you need. A simple model can always be augmented, but simplifying a complex model may not be so easy.

5. Subdivide a complex analysis in to multiple simpler pieces and then assemble the results of the pieces into the final result: "Divide and Conquer."

6. Make all the approximations you can, as soon as you can, justified or not. Plow through the problem, leaving behind a wake of assumptions and approximations. You can't lose by trying.

7. The less work you do, the more valuable the result. You control the algebra. You make the answer come out in Low-Entropy form by applying strategic mental energy before doing any math.

8 . Every problem is not unique; there are problem solving strategies and techniques that apply to almost all engineering problems.

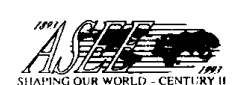

1993 Frontiers in Education Conference

20 
Examples of these strategies and techniques will be discussed as time allows.

During this presentation I expect to be increasingly frequently interrupted and diverted by discussion and argument, leading up to the Big Question: Is it possible, or even desirable, to adopt this approach at a first level?

On the assumption that the answer is positive, we can spend the rest of the time developing specifics and reaching conclusions, perhaps by way of pondering such topics as:

1. How can Design-Oriented Analysis be incorporated into existing curricula? What are the obstacles? Can existing textbooks be used, with additional material?

2. Relationship between Design-Oriented Analysis and simulation. How to persuade students to think before they simulate?

3. Working design engineers are extremely receptive to Design-Oriented Analysis methods; they have often enough fallen victim to algebraic paralysis. Students are less receptive; they still cling to the objective of an exact answer. How can we convince them that these methods really are useful?

This last point $I$ find particularly challenging in my own second-level course. One of my hopes is that students will take to this approach more readily if they are exposed to it the first time around, rather than as a changed approach later after the conventional first approach has already become ingrained.

I have already conducted a three-day workshop on this same topic (the answer to the Big Question was uniformly positive) [3]. Copies of the Summary Report will be available at this Workshop.

[1] R.D.Middlebrook, "Low-Entropy Expressions: The Key to Design-Oriented Analysis," Proc. FIE ‘91, 399-403.

[2] R.D.Middlebrook, "Methods of Design-Oriented Analysis: The Quadratic Equation Revisited," Proc FIE ‘92, 95-102.

[3] Analog Workshop I, Kellogg Continuing Education Center, CalPoly Pomona, June 14 - 16, 1993. Summary Report; Proceedings.

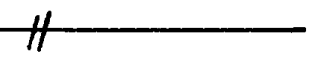

\section{R. David Middlebrook}

R. D. Middlebrook received the B.A. and M.A. degrees from Cambridge University, England, and the M.S. and Ph.D. degrees from Stanford University, Stanford, CA. He is a Fellow of the IEEE, and a Fellow of the IEE (U.K.).

He is Professor of Electrical Engineering at the California Institute of Technology (Caltech). His publications include numerous papers, a book on solid-state device theory, and another on differential ampliffers. He is especially interested in design-oriented circuit analysis and measurement techniques which he teaches at Caltech, and he has conducted short courses on his methods in both Europe and the United States.

Dr. Middlebrook is the recipient of the 1982 IEEE Willtam E. Newell Power Electronics Award for Outstanding Achievement in Power Electronics, and a 1982 Award for Excellence in Teaching, presented by the Board of Directors of the Associated Students of Caltech. In 1984 he received an IEEE Centennial Medal, and in 1991 he was awarded the Edward Longstreth Medal of the Franklin Institute.

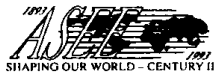

1993 Frontiers in Education Conference

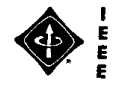

